\title{
Pathogenic substitution of IVS15 + 5G > A in SLC26A4 in patients of Okinawa Islands with enlarged vestibular aqueduct syndrome or Pendred syndrome
}

Akira Ganaha ${ }^{1 * \dagger}$, Tadashi Kaname ${ }^{2 \dagger}$, Kumiko Yanagi $^{2+}$, Kenji Naritomi $^{2 \dagger}$, Tetsuya Tono ${ }^{3 \dagger}$, Shin-ichi Usami ${ }^{4+}$ and Mikio Suzuki ${ }^{1+}$

\begin{abstract}
Background: Pendred syndrome (PS) and nonsyndromic hearing loss associated with enlarged vestibular aqueduct (EVA) are caused by SLC26A4 mutations. The Okinawa Islands are the southwestern-most islands of the Japanese archipelago. And ancestral differences have been reported between people from Okinawa Island and those from the main islands of Japan. To confirm the ethnic variation of the spectrum of SLC26A4 mutations, we investigated the frequencies of SLC26A4 mutations and clinical manifestations of patients with EVA or PS living in the Okinawa Islands.

Methods: We examined 22 patients with EVA or PS from 21 unrelated families in Okinawa Islands. The patient's clinical history, findings of physical and otoscopic examinations, hearing test, and computed tomography (CT) scan of the temporal bones were recorded. To detect mutations, all 21 exons and the exon-intron junctions of SLC26A4 were sequenced for all subjects. Quantitative reverse-transcription polymerase chain reaction (qRT-PCR) for SLC26A4 and calculations using the comparative $C T\left(2^{-\Delta \Delta C T}\right)$ method were used to determine the pathogenicity associated with gene substitutions.
\end{abstract}

Results: SLC26A4 mutations were identified in 21 of the 22 patients. We found a compound heterozygous mutation for IVS15 + 5G > A/H723R in nine patients (41\%), a homozygous substitution of IVS15 + 5G > A in six patients (27\%), and homozygous mutation for H723R in five patients (23\%). The most prevalent types of SLC26A4 alleles were IVS15 + 5G > A and H723R, which both accounted for 15/22 (68\%) of the patients. There were no significant correlations between the types of SLC26A4 mutation and clinical manifestations. Based on qRT-PCR results, expression of SLC26A4 was not identified in patients with the homozygous substitution of IVS15 + 5G > A.

Conclusions: The substitution of IVS15 + 5G > A in SLC26A4 was the most common mutation in uniquely found in patients with PS and EVA in Okinawa Islands. This suggested that the spectrum of SLC26A4 mutation differed from main islands of Japan and other East Asian countries. The substitution of IVS15 + 5G > A leads to a loss of SLC26A expression and results in a phenotype of PS and EVA.

\footnotetext{
* Correspondence: ganahaa@med.u-ryukyu.ac.jp

${ }^{\dagger}$ Equal contributors

'Department of Otorhinolaryngology-Head and Neck Surgery, University of the Ryukyus, Okinawa, Japan

Full list of author information is available at the end of the article
} 


\section{Background}

Profound hearing loss affects about 1 in 300 to 1 in 1000 newborns [1-4], and about one-half of these cases can be attributed to genetic factors [5]. About 51\% of these cases are due to single nucleotide polymorphisms [5]. As to inheritance pattern among monogenic probands, about $1 \%$ is X-linked, $22 \%$ is autosomal dominant, and $77 \%$ is autosomal recessive [5]. Pendred syndrome (PS) is an autosomal recessive disorder characterized by congenital sensorineural hearing loss and goiter [6]. The causative gene for PS and EVA was identified to be $S L C 26 A 4[7,8]$. Enlarged vestibular aqueduct (EVA) is a common inner ear malformation that can be diagnosed radiographically in patients with impaired hearing (Figure 1). EVA is frequently associated with PS [9-11]. In addition to PS, SLC26A4 mutations also cause nonsyndromic hearing loss with EVA in the absence of a thyroid phenotype $[12,13]$.

Previous studies revealed that the spectrum of SLC26A4 mutations varied on the basis of ethnic background $[14,15]$. Tsukamoto et al. [15] demonstrated that SLC26A4 mutations occurred in $90 \%$ of families with a history of PS and in 78\% of families with a history of EVA in Japan. Among these SLC26A4 mutations, H723R was suggested to have a founder effect in the Japanese population.

The Okinawa Islands are the southwestern-most islands of the Japanese archipelago (Figure 2). Previous studies suggested that there were substantial ancestral differences between Okinawa Islands the main islands of Japan [16]. In this study, we examined patients with EVA or PS from the Okinawa Islands to determine the frequencies and the genotypes of SLC26A4 mutations and their clinical manifestations.

\section{Methods}

\section{Subjects}

From May 2008 to July 2012, 22 patients (8 males, 14 females; age range: $0-33$ years; mean age: 5.8 years; median age: 8.5 years; Table 1 ) were diagnosed with PS or EVA in the Department of Otorhinolaryngology, Head and Neck Surgery of the University of the Ryukyus, Japan.
Prior to enrollment, all subjects provided a written informed consent. Our research protocol was approved by the Ethical Review Board of the University of the Ryukyus.

\section{Clinical manifestations of PS and EVA}

Clinical history of 22 patients with neuro-otologic symptoms was recorded. A physical examination, including otoscopy, hearing level test, computed tomography (CT) scan of the temporal bones, and examination for thyroid goiter was conducted.

Depending on a subject's ability, hearing level was determined using auditory brainstem response, conditioned orientated response, or pure tone audiogram. Hearing level was defined as the average of the hearing threshold at $0.5,1.0,2.0$, and $4.0 \mathrm{kHz}$. Hearing was described as: normal, < $20 \mathrm{~dB}$; mild impairment, 21-40 dB; moderate impairment, 41-70 dB; severe impairment, 71-90 dB; and profound impairment, >91 dB.

Neck palpation or echography of the neck was performed in all patients, to determine thyroid goiter. In addition, their serum levels of thyroid-stimulating hormone (TSH) and free thyroxine (FT4) were measured to evaluate thyroid function (normal values: $0.9-1.6 \mathrm{ng} / \mathrm{dl}$ and $0.5-5.0 \mathrm{mU} / \mathrm{l}$, respectively). A perchlorate test was not performed.

High-resolution temporal bone CT was performed in all patients to determine if there were any other inner ear malformations in addition to EVA. EVA was defined as a vestibular aqueduct with a diameter of $>1.5 \mathrm{~mm}$ at the midpoint between the common crus of the semicircular canal and the external aperture of the vestibular aqueduct on CT [17].

Mondini dysplasia was defined when the cochlea consisted of 1.5 turns in which the middle and apical turns had coalesced to form a cystic apex due to the absence of the interscalar septum $[18,19]$.

Vestibular enlargement was defined when the ratio of the membranous vestibule diameter to the inner ear diameter of the lateral semicircular canal was $>1.2$ [20].

Vertigo was investigated based on spontaneous nystagmus, caloric vestibular test or patients' self-reporting of past episode. The spontaneous nystagmus was evaluated

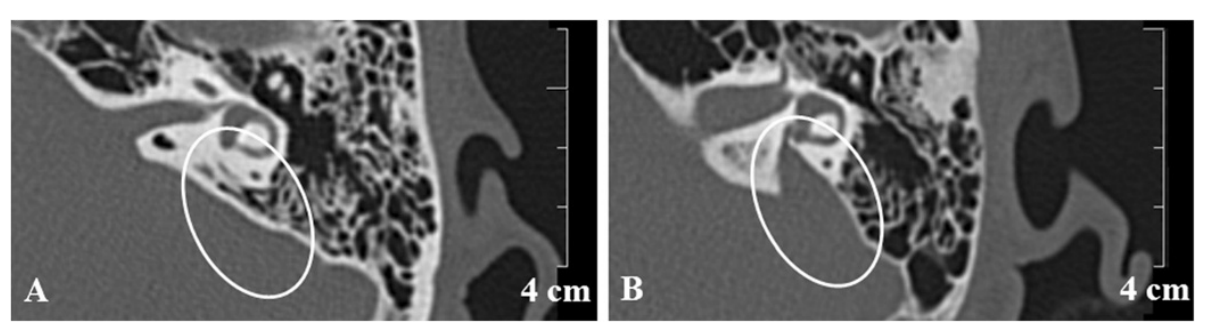

Figure 1 Computed tomography of the temporal bone showing an enlarged vestibular aqueduct. Circles show the vestibular aqueduct. The vestibular aqueduct is not identified in control subject (A). The enlarged vestibular aqueduct is identified in a patient with EVA (B). 


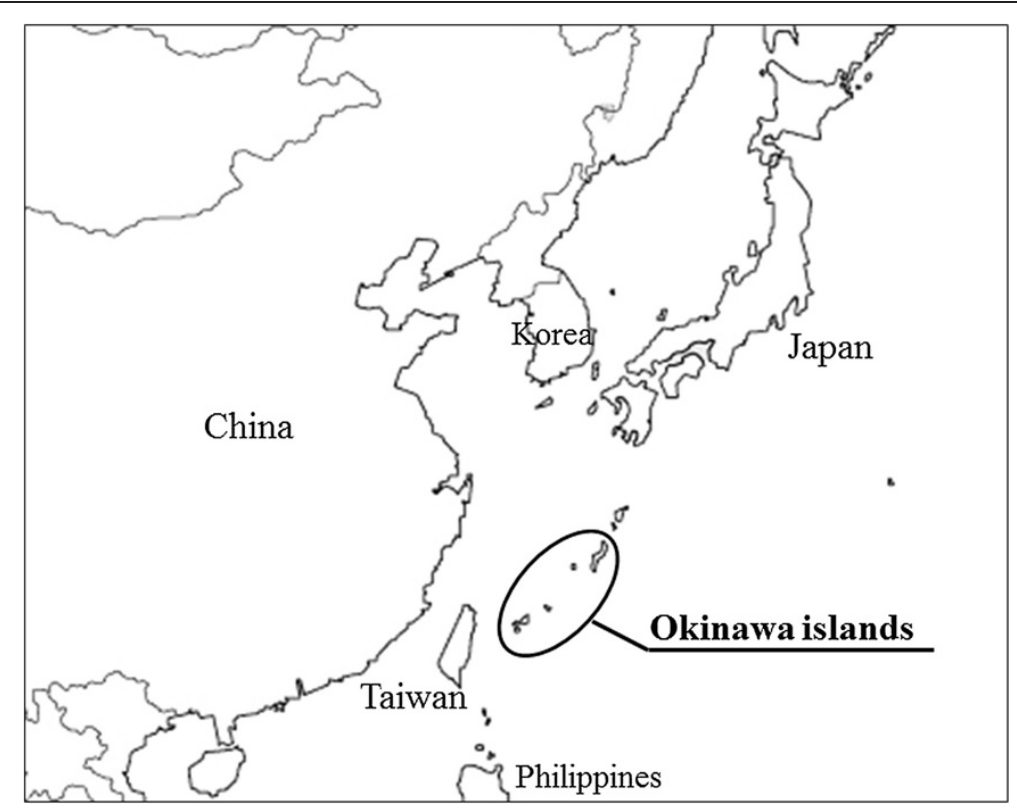

Figure 2 Location of the Okinawa islands in relation to East Asia. The Okinawa islands are located between Taiwan and the Japanese island of Kyushu. The Japanese archipelago comprises Hokkaido, Honshu, Kyusyu, and the Okinawa islands, as well as some smaller islands.

using Frenzel's glass or infrared CCD camera (IRN-1, Morita, Kyoto, Japan).

\section{SLC26A4 genotyping}

Genomic DNA was extracted from whole blood using a QIAamp DNA Blood Mini Kit (Qiagen, Hilden, Germany). To detect mutations, all 21 exons and the exon-intron junctions of SLC26A4 were sequenced for all subjects. A 35 step cycle of Polymerase chain reactions (PCR) was performed as follows: initial denaturation at $94^{\circ} \mathrm{C}$ for $5 \mathrm{~min} ; 35$ cycles of $94^{\circ} \mathrm{C}$ for $40 \mathrm{~s}, 60^{\circ} \mathrm{C}$ for $40 \mathrm{~s}$, and $72^{\circ} \mathrm{C}$ for $1 \mathrm{~min}$; and a final extension at $72^{\circ} \mathrm{C}$ for $5 \mathrm{~min}$. PCR reactions were run using a programmable thermal cycler $\left(\right.$ Verti $^{\text {tw }}$ 96-Well Thermal Cycler, Applied Biosystems, CA, USA).

PCR products were purified using a Wizard ${ }^{\circ} \mathrm{SV}$ Gel and PCR Clean-Up System (Promega, WI, USA) and directly sequenced using an ABI PRISM $3130 \times 1$ Genetic Analyzer (Applied Biosystems). The sequences obtained were aligned and compared using the BLAST program with known human genome sequences available in the GenBank database.

We surveyed the substitution IVS15 + 5G > A in 100 healthy objects as control.

The genotype of the IVS15 + 5G > A was detected by digestion of the PCR product with the restriction enzyme SspI (New England Biolabs, Ipswich, MA, U.S.A).

\section{Total RNA isolation and reverse-transcription}

Total RNA was isolated from leukocytes using a QIAamp RNA Blood Mini Kit (Qiagen) according to the manufacturer's protocol. Before cDNA synthesis, residual DNA was removed by incubation with RNase-free DNase I (Ambion Inc., City, TX, USA). Then, total RNA was reverse transcribed using a TaKaRa Prime Script High Fidelity $\mathrm{RT}^{\ominus}$ Kit (TaKaRa, Tokyo, Japan) according to the manufacturer's protocol. Possible contaminating genomic DNA in RNA samples was determined by electrophoresis.

\section{Quantitative nested real-time PCR}

Nested real-time quantitative (q) PCR was performed to investigate the level of SLC26A4 expression in the blood.

\section{First-step PCR (conventional PCR)}

A conventional PCR assay was performed in a $10 \mu \mathrm{l}$ reaction mixture that included $2 \mu \mathrm{l}$ of cDNA, 0.5 units of DNA Taq polymerase (TaKaRa), $2.5 \mathrm{mM}$ deoxynucleotide triphosphates (dNTPs), $1 \mu \mathrm{M}$ forward and reverse primers for first-step PCR (Table 2), $10 \times$ buffer, and $1.875 \mathrm{mM}$ $\mathrm{MgCl}_{2}$, with distilled water $\left(\mathrm{H}_{2} \mathrm{O}\right)$ for the final reaction volume of $10 \mu \mathrm{l}$. A 33 step cycle of PCR were performed as follows: $94^{\circ} \mathrm{C}$ for $5 \mathrm{~min}, 33$ cycles of $94^{\circ} \mathrm{C}$ for $30 \mathrm{~s}, 60^{\circ} \mathrm{C}$ for $30 \mathrm{~s}, 72^{\circ} \mathrm{C}$ for $40 \mathrm{~s}$, and a final extension at $72^{\circ} \mathrm{C}$ for $5 \mathrm{~min}$.

\section{Second-step PCR (quantitative nested PCR)}

Following the first PCR, a second PCR was performed using a set of internal primers (Table 2). The reaction mixture contained $1 \mu \mathrm{l}$ of the first PCR product (diluted 10-fold), $10 \mu \mathrm{l}$ of SYBR Premix Ex Taq, and $0.2 \mu \mathrm{M}$ of the internal forward and reverse primers; the final 
Table 1 Summary of clinical features of 22 patients

\begin{tabular}{|c|c|c|c|c|c|c|c|c|c|c|}
\hline \multicolumn{3}{|c|}{ Age (years) } & \multicolumn{3}{|c|}{ CT } & \multicolumn{2}{|r|}{ PTA } & Vertigo & \multicolumn{2}{|r|}{ Thyroid } \\
\hline 1 & 3 & $\mathrm{R}$ & $\begin{array}{c}\text { EVA } \\
+\end{array}$ & $\begin{array}{c}\text { MD } \\
+\end{array}$ & $\begin{array}{c}\mathrm{VE} \\
+\end{array}$ & $\begin{array}{c}\mathrm{HL}(\mathbf{d B}) \\
\mathrm{SO}\end{array}$ & $\begin{array}{c}\text { Conductive hearing loss } \\
\text { unknown }\end{array}$ & - & $\begin{array}{c}\text { Goiter } \\
-\end{array}$ & $\begin{array}{c}\text { Thyroid functio } \\
\text { normal }\end{array}$ \\
\hline & & $\mathrm{L}$ & + & + & + & $\mathrm{SO}$ & unknown & & & \\
\hline \multirow[t]{2}{*}{2} & 14 & $\mathrm{R}$ & + & + & - & 105 & + & - & + & normal \\
\hline & & $\mathrm{L}$ & + & + & - & 96 & + & & & \\
\hline \multirow[t]{2}{*}{3} & 21 & $\mathrm{R}$ & + & + & + & 73 & + & + & + & normal \\
\hline & & $\bar{L}$ & + & + & + & 91 & + & & & \\
\hline \multirow[t]{2}{*}{4} & 21 & $\mathrm{R}$ & + & - & - & 81 & + & + & + & normal \\
\hline & & $\bar{L}$ & + & - & - & 85 & + & & & \\
\hline \multirow[t]{2}{*}{5} & 28 & $\mathrm{R}$ & + & + & + & 96 & + & + & + & normal \\
\hline & & $\mathrm{L}$ & + & + & + & $\mathrm{SO}$ & + & & & \\
\hline \multirow[t]{2}{*}{6} & 33 & $\mathrm{R}$ & + & + & - & 101 & + & + & + & normal \\
\hline & & $\bar{L}$ & + & + & + & 106 & + & & & \\
\hline \multirow[t]{2}{*}{7} & 1 & $\mathrm{R}$ & + & + & - & SO & unknown & - & - & normal \\
\hline & & $\mathrm{L}$ & + & + & + & SO & unknown & & & \\
\hline \multirow[t]{2}{*}{8} & 1 & $\mathrm{R}$ & + & - & - & $\mathrm{SO}$ & unknown & - & - & normal \\
\hline & & $\mathrm{L}$ & + & - & - & 103 & unknown & & & \\
\hline \multirow[t]{2}{*}{9} & 2 & $\mathrm{R}$ & + & + & - & 101 & unknown & - & - & normal \\
\hline & & $\mathrm{L}$ & + & + & - & 100 & unknown & & & \\
\hline \multirow[t]{2}{*}{10} & 12 & $R$ & + & - & - & 95 & + & - & + & normal \\
\hline & & $\bar{L}$ & + & - & - & 100 & + & & & \\
\hline 11 & 29 & $\mathrm{R}$ & + & + & + & 85 & + & - & - & \\
\hline & & $\mathrm{L}$ & + & + & + & 110 & + & & & \\
\hline 12 & 0 & $R$ & + & - & - & 55 & unknown & + & - & normal \\
\hline & & L & + & - & - & 73 & unknown & & & \\
\hline 13 & 3 & $\mathrm{R}$ & + & - & + & 85 & unknown & + & - & normal \\
\hline & & $\bar{L}$ & + & + & + & 58 & + & & & \\
\hline 14 & 5 & $R$ & + & + & + & 95 & + & + & - & normal \\
\hline & & $\mathrm{L}$ & + & + & + & 93 & + & & & \\
\hline 15 & 5 & $R$ & + & + & + & 103 & + & - & - & normal \\
\hline & & $\bar{L}$ & + & + & + & 100 & unknown & & & \\
\hline 16 & 6 & $\mathrm{R}$ & + & - & - & 81 & + & + & - & normal \\
\hline & & $\bar{L}$ & + & - & - & 91 & + & & & \\
\hline 17 & 7 & $R$ & + & - & - & 83 & + & - & - & normal \\
\hline & & $\mathrm{L}$ & + & - & + & 81 & + & & & \\
\hline 18 & 14 & $\mathrm{R}$ & + & + & + & 96 & + & - & + & normal \\
\hline & & $\mathrm{L}$ & + & + & + & 91 & + & & & \\
\hline 19 & 16 & $R$ & + & - & + & 91 & + & - & + & normal \\
\hline & & $\bar{L}$ & - & - & + & 21 & - & & & \\
\hline 20 & 26 & $R$ & + & - & - & 98 & + & + & - & normal \\
\hline & & L & + & - & + & 103 & + & & & \\
\hline 21 & 5 & $R$ & + & + & + & 85 & + & - & - & normal \\
\hline & & $\mathrm{L}$ & + & + & - & 97 & + & & & \\
\hline 22 & 10 & $R$ & + & - & - & 53 & + & - & - & normal \\
\hline & & $\bar{L}$ & - & - & - & 15 & - & & & \\
\hline
\end{tabular}

EVA enlarged vestibular aqueduct, MD Mondini malformation, VE vestibular enlargement, PTA pure tone audiogram, $H L$ hearing level, SO scale out, NA no available data. 
Table 2 Primer sequences used for nested real-time PCR

\begin{tabular}{|c|c|c|c|c|}
\hline Nested PCR assay & & & Sequence & PCR product size (bp) \\
\hline \multirow[t]{2}{*}{ First-step PCR (external primer) } & Exon 14 & forward & TCTTGGAATGGCCTTGGAAGC & 282 \\
\hline & Exon 17 & reverse & TGAAACAGCATCACTTATGATGC & \\
\hline \multirow[t]{2}{*}{ Second-step PCR (internal primer) } & Exon 15 & forward & TGAAGAACCTCAAGGAGTGAAG & 154 \\
\hline & Exon 16 & reverse & TTTCTGTATTTCCTCAGCGCT & \\
\hline
\end{tabular}

reaction volume was adjusted to $20 \mu \mathrm{l}$ with distilled $\mathrm{H}_{2} \mathrm{O}$. A Light Cycler real-time quantitative PCR system (Roche, Basel Switzerland) was used for amplification and detection of the PCR products. A 40 step cycle of thermal cycler program was performed as follows: denaturation at $95^{\circ} \mathrm{C}$ for $5 \mathrm{~min} ; 40$ cycles of $95^{\circ} \mathrm{C}$ for $10 \mathrm{~s}$, $60^{\circ} \mathrm{C}$ for $20 \mathrm{~s}$, and $72^{\circ} \mathrm{C}$ for $40 \mathrm{~s}$; followed by recording the fluorescence values after each elongation step and melting curve analysis with denaturation at $95^{\circ} \mathrm{C}$ for $5 \mathrm{~s}$, annealing at $65^{\circ} \mathrm{C}$ for $1 \mathrm{~min}$, and redenaturation by increasing the temperature to $95^{\circ} \mathrm{C}$. The second-step PCR products were separated by $1.5 \%$ agarose gel electrophoresis, stained with ethidium bromide, and visualized by UV transillumination. For this analysis, we used three control subjects with no mutations (wild type), three patients compound heterozygous for IVS15 + 5G > A/H723R, and three patients homozygous for IVS15 + $5 \mathrm{G}>\mathrm{A}$.

\section{Validation of comparative CT $\left(2^{-\Delta \Delta C T}\right)$ method and calculations for quantifying SLC26A4 mRNA}

We used the CT $\left(2^{-\Delta \Delta C \mathrm{~T}}\right)$ method by assuming approximately equal amplification efficiencies for both target and reference genes. This prerequisite was verified by performing a validation experiment using both SLC26A4 and a housekeeping gene. Calculations were made using the comparative CT $\left(2^{-\triangle \Delta C T}\right)$ method. GAPDH (glyceraldehyde 3-phosphate dehydrogenase), $P G K-1$ (phosphoglycerate kinase 1), and $A C T B$ (actin beta) were used as internal reference genes for PCR normalization with regard to the amount of RNA added to the reverse transcription reactions. Normalized results were expressed as the mean ratio of $S L C 26 A 4$ mRNA to GAPDH mRNA, PGK-1 mRNA, and ACTB mRNA. To evaluate relative transcript levels, the threshold cycle value $(\mathrm{Ct})$ of each sample was used to calculate and compare the $\Delta \mathrm{Ct}$ of each sample to that of the control subject and patients with a compound heterozygous for IVS15 + 5G > A/H723R, and a homozygous for IVS15 + 5G $>$ A. $\Delta \Delta \mathrm{CT}$ was also calculated to compare the transcript levels in the control subject, and patients with a compound heterozygous for IVS15 + 5G > A/H723R, and a homozygous for IVS15 + $5 \mathrm{G}>\mathrm{A}$. The transcript levels were calculated in each genotype with three subjects and each subject was calculated in triplicate.

\section{Results}

\section{Mutation analysis for SLC26A4}

By direct DNA sequence analysis, SLC26A4 mutations were observed in 21 of 22 patients. Among the 21 patients with mutations, a compound heterozygous mutation for IVS15 + 5G > A/H723R was identified in nine patients (Figure $3 \mathrm{C}, \mathrm{D}$ ), a homozygous mutation for H723R was identified in five patients (Figure 3E), and a homozygous substitution of IVS15 + 5G > A was identified in six patients (Figure 3F). A compound heterozygous substitutions for IVS15 + 5G > A/T527P was identified in one subject. We could not identify any SLC26A4 mutations in one subject (Table 3). We could not find the substitution IVS15 + 5G > A in 100 control objects.

\section{Clinical characteristics}

Table 1 summarizes the clinical characteristics of all 22 subjects. High-resolution temporal bone CT scans revealed that bilateral EVA was present in 20 patients and unilateral EVA was present in other two. Mondini dysplasia and vestibular enlargement was observed in 17 ears $(17 / 44 ; 39 \%)$ and 22 ears $(22 / 44 ; 50 \%)$, respectively.

Hearing loss grades in the affected ears ranged from moderate to profound in the patients with EVA (Table 1). The hearing levels of the two unaffected ears were normal and mild hearing loss, respectively. Table 4 shows the hearing level distributions based on genotypes. No significant differences were expected in the distributions for hearing level among the five genotype groups due to the small sample of only 22 patients.

Neck examinations revealed thyroid goiters in 8 of 22 patients. Overall, $0 \%(0 / 11)$ and $73 \%(8 / 11)$ of the patients younger and older than 10 years of age, respectively, had a thyroid goiter. Their serum FT4 and TSH levels were within the normal ranges. There is no relation between occurrence of goiter and mutation genotypes.

\section{SLC26A4 expression in patients with IVS15 +5 G $>$ A}

Electrophoretic separation of the real-time PCR products did not exhibit any bands in patients with the homozygous substitution for IVS15 + 5G > A (Figure 4C).

Because the SLC26A4 expression levels were not high in blood samples, we investigated its expression using nested real-time qPCR for three control subjects, three 


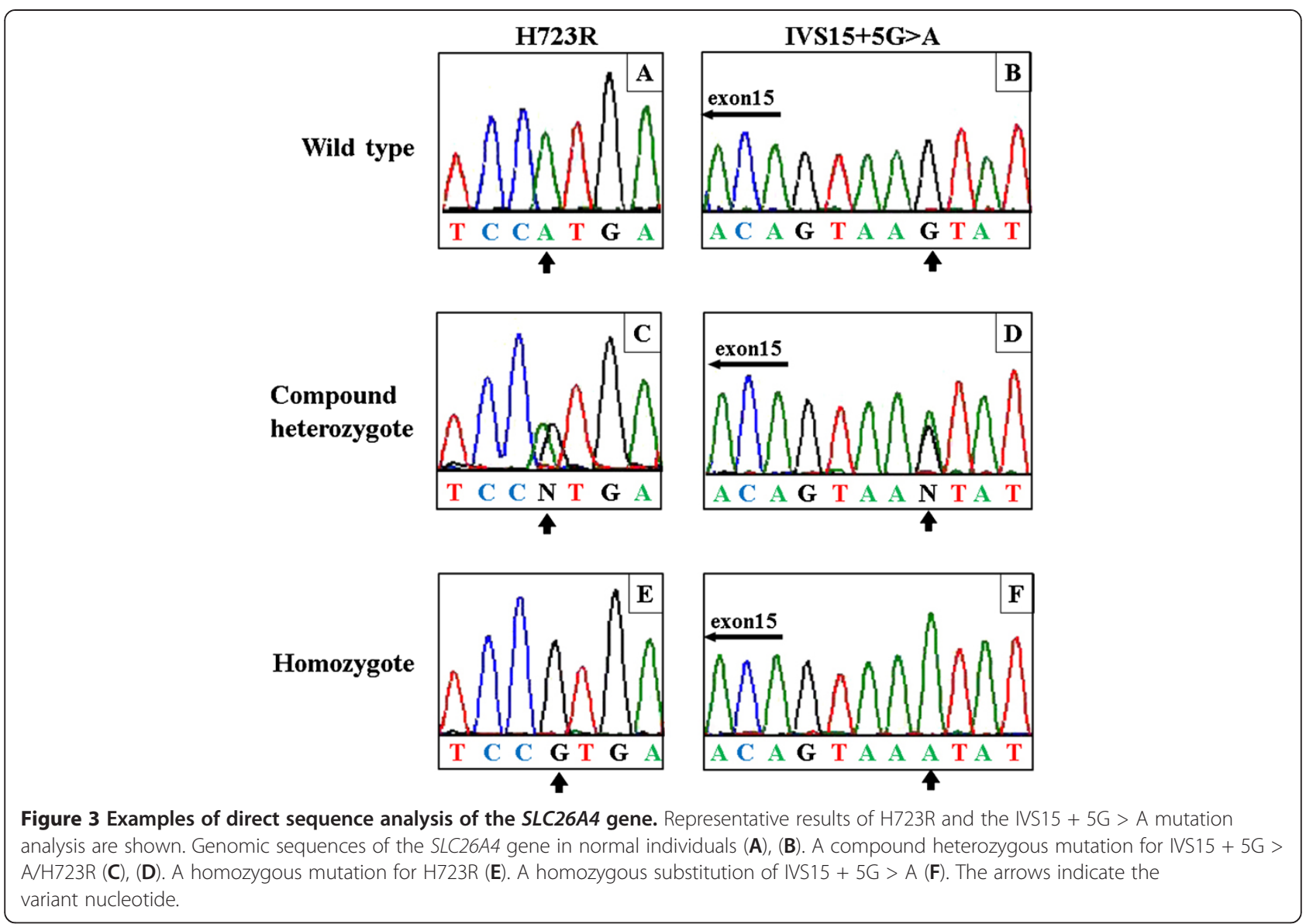

patients with the compound heterozygous mutation for IVS15 + 5G > A/H723R, and three patients with the homozygous substitution for IVS15 + 5G > A. The control subjects had normal hearing without any malformations of the inner or middle ear and no family history of hearing loss. After obtaining a written informed consent, blood samples were collected from each subject and were subjected to Real-time PCR with SYBR Green and the expression level was evaluated using the comparative CT $\left(2^{-\Delta \Delta \mathrm{CT}}\right)$ method. The relative SLC26A4 expression levels in the control no.1, control no. 2 and control no. 3 with no SLC26A4 mutations were $9089 \pm 441.5$ (standard deviation), $2417 \pm 189.5$, and $4956 \pm 260.4$ respectively. In patient no.12, patient no.14 and patient no.16 with a compound heterozygous mutation for IVS15 $+5 \mathrm{G}>\mathrm{A} / \mathrm{H} 723 \mathrm{R}$ were $979.5 \pm 79.12,2846 \pm 206.5$ and $1183 \pm 33.93$ respectively. In patient no.1, patient no. 2 and patient no. 4 with a homozygous substitution for IVS15 + 5G > A were $1.96 \times$ $10^{-4} \pm 7.66 \times 10^{-5}, \quad 5.76 \times 10^{-5} \pm 3.37 \times 10^{-6}$ and $4.35 \times$ $10^{-5} \pm 8.09 \times 10^{-6}$ respectively (Figure 5 ).

Based on the results of both electrophoresis and RTnested qPCR, no $S L C 26 A 4$ expression was observed in patients with homozygous substitution of IVS15 + 5G > A.

\section{Discussion}

Correlations between SLC26A4 genotypes and hearing phenotypes

Hearing loss in patients with EVA and PS is usually apparent at the pre- or perilingual stage [6,21]. Hearing loss in EVA and PS is sensorineural with some mixed hearing loss in the low-frequency range [22-27]. The hearing level sometimes deteriorates suddenly and may be followed by a partial recovery, such as with fluctuating hearing loss $[28,29]$. In our study, hearing loss was detected at the pre- or perilingual stage in all cases except for two cases of unilateral EVA. However, in all cases, hearing levels eventually deteriorated to severe or profound loss (Table 1) and were permanent with or without hearing fluctuation or stepwise hearing deterioration. No significant differences were observed in the hearing levels among the five genotypes (Table 4).

\section{Correlations between SLC26A4 genotypes and thyroid phenotype}

SLC26A4 encodes for the $86 \mathrm{kDa}$ transmembrane protein pendrin $[7,30]$. In the thyroid, this protein acts as co-transporter of chloride and iodine in the thyroid 
Table 3 Distribution of SLC26A4 genotypes of 22 patients

\begin{tabular}{|c|c|c|c|c|c|}
\hline & $\begin{array}{l}\text { Age at onset } \\
\text { of hearing } \\
\text { loss (years) }\end{array}$ & $\begin{array}{c}\text { Age at } \\
\text { genetic } \\
\text { test (years) }\end{array}$ & Sex & Allele 1 & Allele 2 \\
\hline 1 & 0 & 3 & $M$ & IVS15 + 5G > A & IVS15 + 5G > A \\
\hline 2 & 2 & 14 & $\mathrm{~F}$ & $\mathrm{IVS} 15+5 \mathrm{G}>\mathrm{A}$ & $\mathrm{IVS} 15+5 \mathrm{G}>\mathrm{A}$ \\
\hline 3 & 3 & 21 & $\mathrm{~F}$ & IVS15 + 5G > A & IVS15 + 5G > A \\
\hline 4 & 2 & 22 & $\mathrm{~F}$ & IVS15 + 5G > A & IVS15 + 5G > A \\
\hline 5 & 0 & 23 & $M$ & $\mathrm{IVS} 15+5 \mathrm{G}>\mathrm{A}$ & $\mathrm{IVS} 15+5 \mathrm{G}>\mathrm{A}$ \\
\hline 6 & 0 & 29 & $\mathrm{~F}$ & IVS15 + 5G > A & $\mathrm{IVS} 15+5 \mathrm{G}>\mathrm{A}$ \\
\hline 7 & 0 & 1 & $\mathrm{~F}$ & $\mathrm{H} 723 \mathrm{R}$ & $\mathrm{H} 723 \mathrm{R}$ \\
\hline 8 & 1 & 1 & $\mathrm{~F}$ & $\mathrm{H} 723 \mathrm{R}$ & $\mathrm{H} 723 \mathrm{R}$ \\
\hline 9 & 4 & 2 & $M$ & $\mathrm{H} 723 \mathrm{R}$ & $\mathrm{H} 723 \mathrm{R}$ \\
\hline 10 & 0 & 12 & $\mathrm{~F}$ & $\mathrm{H} 723 \mathrm{R}$ & $\mathrm{H} 723 \mathrm{R}$ \\
\hline 11 & 5 & 29 & $M$ & $\mathrm{H} 723 \mathrm{R}$ & $\mathrm{H} 723 \mathrm{R}$ \\
\hline 12 & 0 & 0 & $M$ & IVS15 + 5G > A & $\mathrm{H} 723 \mathrm{R}$ \\
\hline 13 & 2 & 3 & M & IVS15 + 5G > A & $\mathrm{H} 723 \mathrm{R}$ \\
\hline 14 & 0 & 5 & $\mathrm{~F}$ & IVS15 + 5G > A & $\mathrm{H} 723 \mathrm{R}$ \\
\hline 15 & 1 & 5 & $\mathrm{~F}$ & $\mathrm{IVS} 15+5 \mathrm{G}>\mathrm{A}$ & $\mathrm{H} 723 \mathrm{R}$ \\
\hline 16 & 0 & 6 & $\mathrm{~F}$ & $\mathrm{IVS} 15+5 \mathrm{G}>\mathrm{A}$ & $\mathrm{H} 723 \mathrm{R}$ \\
\hline 17 & 2 & 7 & $\mathrm{~F}$ & IVS15 + 5G > A & $\mathrm{H} 723 \mathrm{R}$ \\
\hline 18 & 2 & 14 & $\mathrm{~F}$ & $\mathrm{IVS} 15+5 \mathrm{G}>\mathrm{A}$ & $\mathrm{H} 723 \mathrm{R}$ \\
\hline 19 & 7 & 16 & $\mathrm{~F}$ & IVS15 + 5G > A & $\mathrm{H} 723 \mathrm{R}$ \\
\hline 20 & 5 & 26 & $M$ & $\mathrm{IVS} 15+5 \mathrm{G}>\mathrm{A}$ & $\mathrm{H} 723 \mathrm{R}$ \\
\hline 21 & 1 & 5 & $M$ & $\mathrm{H} 723 \mathrm{R}$ & T527P \\
\hline 22 & 7 & 10 & $\mathrm{~F}$ & ND & ND \\
\hline
\end{tabular}

ND not determined.

[31,32]. In PS patients, a mutation in SLC26A4 results in reduced pendrin-induced chloride and iodide transport and, ultimately, goiter [33].

Goiter usually develops around the end of the first decade of life or during young adulthood, although the time of onset and severity vary considerably among patients [12,34], and even within families [35]. Despite an impaired incorporation of iodide, most patients with PS are clinically and biochemically euthyroid $[21,34,36]$.
To our knowledge, no previous studies have investigated correlations between SLC26A4 genotypes and the thyroid phenotype. In the present study, PS was diagnosed in 8 of 11 patients older than 10 years of age, but not in any of the 11 patients who were younger than 10 years of age. This indicates that it is difficult to diagnose PS before the age of 10 years.

Thyroid function was normal in all of the 21 patients we examined, as demonstrated by their normal serum concentrations of FT4 and TSH. There were no significant differences in serologic thyroid test results and goiter status among patients with homozygous substitution for IVS15 + 5G > A, the H723R homozygous mutation, or compound heterozygous mutation for IVS15 + 5G > A/H723R. Therefore, our results indicate that serologic testing of FT4 and TSH levels is not useful to distinguish between individuals with PS or EVA.

\section{Distributions of SLC26A4 mutations in EVA and PS patients in Okinawa Islands}

It was previously reported that the spectrum of $S L C 26 A 4$ mutations varied based on ethnic background $[35,36]$. H723R and IVS7-2A > G are prevalent alleles that account for the majority of the observed SLC26A4 mutations in East Asian populations [35]. In the Japanese population, H723R was the most common mutation $[15,36,37]$. In Chinese and Taiwanese populations, IVS7$2 \mathrm{~A}>\mathrm{G}$ was the most common mutation [38-40], whereas in the Korean population, H723R and IVS7-2A > G were the most frequent and accounted for $60.2 \%(47 / 78)$ and $30.7 \%(24 / 78)$ of the mutated alleles, respectively [41].

Ancestral differences have been reported between people from Okinawa Islands and those from the main islands of Japan based on single-nucleotide polymorphism genotypes [16]. We analyzed SLC26A4 mutations among 22 patients with EVA or PS from 21 unrelated families. H723R have been reported as the most common mutation found in the main islands of Japan. As with H723R mutation, IVS15 + 5G > A substitution was

Table 4 Clinical features in different genotype groups

\begin{tabular}{|c|c|c|c|c|c|c|c|c|}
\hline \multirow[t]{2}{*}{ Genotype } & \multicolumn{5}{|c|}{ Hearing level } & \multicolumn{2}{|c|}{ CT } & \multirow[t]{2}{*}{ Vertigc } \\
\hline & Normal & Mild & Moderate & Severe & Profound & MD & VE & \\
\hline IVS15 + 5 G > A homozygous $(n=6)$ & 0 & 0 & 0 & 3 & 9 & $6 / 12$ & $6 / 12$ & $4 / 6$ \\
\hline H723R homozygous $(n=5)$ & 0 & 0 & 0 & 1 & 9 & $4 / 10$ & $3 / 10$ & $0 / 5$ \\
\hline IVS15 + 5 G > A/H723R $(n=9)$ & 0 & 1 & 2 & 4 & 11 & $5 / 18$ & $11 / 18$ & $4 / 9$ \\
\hline IVS15 + 5G > /T527P $(n=1)$ & 0 & 0 & 0 & 1 & 1 & $2 / 2$ & $1 / 2$ & $0 / 1$ \\
\hline No mutation $(n=1)$ & 1 & 0 & 1 & 0 & 0 & $0 / 2$ & $0 / 2$ & $0 / 1$ \\
\hline Subtotal & 1 & 1 & 3 & 9 & 30 & $17 / 44$ & $21 / 44$ & $8 / 22$ \\
\hline Total & & & 44 & & & & & \\
\hline
\end{tabular}




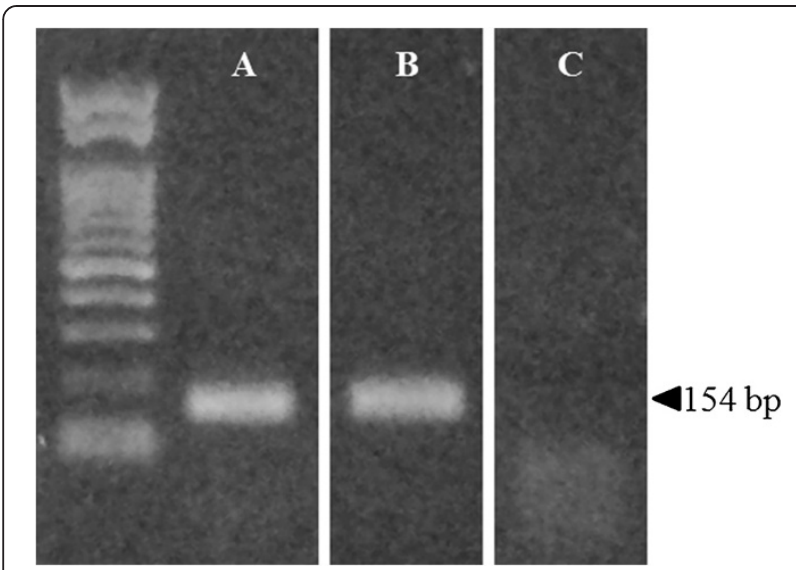

Figure 4 Expression of the SLC26A4 gene in patients with PS or EVA. The expected RT-nested PCR amplification product of SLC26A4 was 154 base pairs (bp) in length. Agarose gel electrophoresis shows the $154 \mathrm{bp}$ band for the control subject (A) and the patient with IVS15 + 5G > A/H723R compound heterozygous mutation (B); however, there was no band for the patient with IVS15 + 5G > A homozygous substitution (C).

also identified most frequently in 15 of 22 of our Okinawa patients. The substitution of IVS15 + 5G > A in one allele have been reported only 10 cases in Asian populations [36,42-45]. Thus, IVS15 + 5G > A was the characteristic SLC26A4 gene mutation among patients in Okinawa Islands, indicating a difference in the spectrum of SLC26A4 mutations among patients in Okinawa Islands compared with patients in other

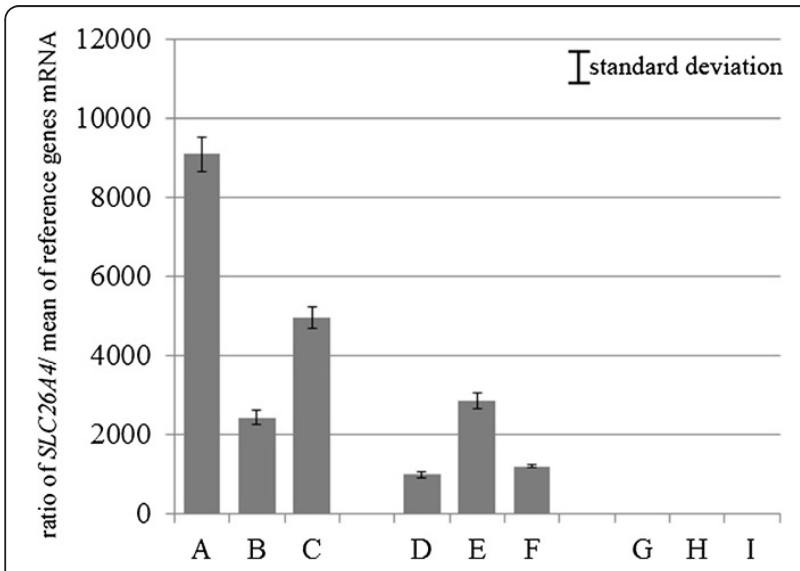

Figure 5 Relative expression of the SLC26A4 gene in control subjects and in patients with a homozygous mutation of IVS15 + 5G > A or compound heterozygous mutation of IVS15 + 5G > A/H723R. The ratio of SLC26A4 mRNA to GAPDH mRNA is shown in three control subjects $(\mathbf{A}, \mathbf{B}, \mathbf{C})$, three patients with compound heterozygous mutation of IVS15 +5G > A/H723R (D, E, F), and three patients with IVS15 + 5G > A homozygous substitution $(\mathbf{G}, \mathbf{H}, \mathbf{I})$. No expression of SLC26A4 was observed in the three patients with the IVS15 + 5G > A homozygous substitution $(\mathbf{G}, \mathbf{H}, \mathbf{I})$. All experiments were done in tripricate. populations. These results suggest that this SLC26A4 mutation may have originated from a common ancestor.

\section{Pathogenic effect of IVS15 + 5G > A substitution}

The heterozygous substitution of IVS15 +5G > A has been assumed to cause aberrant splicing [36,42-45]. However, Yang et al. [42] could not find any abnormal RT-PCR products related to the size for SLC26A4 sequence analysis in patients with splice mutation. Because its pathogenicity was only implicated on the basis of uncommon polymorphisms, the pathogenic potential of IVS15 + 5G > A still remains unknown.

Substitutions near the canonical splice sites are difficult to classify as pathogenic or non-disease causing. Because such substitutions affect proper RNA splicing but some substitutions do not cause any effect [46-48]. Thus, it is important to determine the pathogenic effect of a particular substitution near the donor site by mRNA analysis [48]. We investigated SLC26A4 expression in patients with compound heterozygous mutation for IVS15 + 5G > A/H723R and homozygous substitution for IVS15 + 5G > A by RT-PCR and RT-real time PCR by targeting genes around these mutations. No aberrant PCR products were detected in the patient with heterozygous substitution of IVS15 + 5G > A (Figure 4B), which suggests that IVS15 + 5G > A does not cause aberrant splicing, as also argued by Yang et al. However, in patients with the homozygous substitution of IVS15+ $5 \mathrm{G}>\mathrm{A}, \mathrm{SLC} 26 \mathrm{A4}$ was not expressed, as shown in Figure 4 . In addition, for patients with the heterozygous substitution, SLC26A4 expression was reduced from the normal control level. These findings suggest that IVS15 + $5 \mathrm{G}>$ A disrupts pre-mRNA splicing and causes the loss of SLC26A4 expression. The patients in Yang et al. [42] were heterozyote so that Yang et al. [42] most likely amplified the non-mutated allele. Taken together, our results indicate that the substitution of IVS15 + 5G > A is a lossof-function mutation caused by a loss of SLC26A4 expression.

\section{Conclusions}

We found no correlations between the type of SLC26A4 mutation and hearing levels or the thyroid phenotype. Moreover, thyroid testing using serum FT4 and TSH levels was not useful for distinguishing between individuals with PS and EVA.

The substitution of IVS15 + 5G > A in the SLC26A4 was unique and the most common in PS and EVA patients from Okinawa Islands. This supports that the spectrum of SLC26A4 mutations differs by geographic area in East Asia. Our qPCR results for SLC26A4 indicate that the substitution of IVS15 + 5G > A should be a pathogenic mutation that leads to a loss of SLC26A4 expression and results in a phenotype of PS and EVA. 


\section{Competing interests}

The authors declare that they have no competing interests.

\section{Authors' contributions}

AG diagnosed the patients, collected clinical data, performed the experiments, and wrote the manuscript. TK, KY, and SU carried out data analysis. KN, $\Pi$, and MS edited the manuscript and supervised the project. All authors read and approved the final manuscript.

\section{Acknowledgements}

This work was supported in part by the Japan Society for the Promotion of Science (JSPS) KAKENHI Grant-in-Aid for Young Scientists (B) Number 23791914, by Special Account Budget for Education and Research from the Japan Ministry of Education and by research grants from the Japan Ministry of Health, Labor, and Welfare.

\section{Author details}

${ }^{1}$ Department of Otorhinolaryngology-Head and Neck Surgery, University of the Ryukyus, Okinawa, Japan. ${ }^{2}$ Department of Medical Genetics, University of the Ryukyus, Okinawa, Japan. ${ }^{3}$ Department of Otorhinolaryngology-Head and Neck Surgery, University of Miyazaki, Miyazaki, Japan. ${ }^{4}$ Department of Otorhinolaryngology, Shinshu University School of Medicine, Nagano, Japan.

Received: 18 January 2013 Accepted: 17 May 2013

Published: 24 May 2013

\section{References}

1. Downs MP: Universal newborn hearing screening-the Colorado story. Int J Pediatr Otorhinolaryngol 1995, 32:257-259.

2. Mehl AL, Thomson V: Newborn hearing screening: the great omission. Pediatrics 1998, 101:E4.

3. Mehl AL, Thomson $\mathrm{V}$ : The Colorado newborn hearing screening project, 1992-1999: on the threshold of effective population-based universal newborn hearing screening. Pediatrics 2002, 109:E7.

4. Bitner-Glindzicz M: Hereditary deafness and phenotyping in humans. Br Med Bull 2002, 63:73-94.

5. Morton NE: Genetic epidemiogy of hearing impairment. Ann NY Acad Sci 1991, 630:16-31.

6. Pendred V: Deaf-mutation and goiter. Lancet 1896, 2:532.

7. Everett L, Glaser B, Beck J, Idol J, Buchs A, Heyman M, Adawi F, Hazani E, Nassir E, Baxevanis A, Sheffield V, Green E: Pendred syndrome is caused by mutations in a putative sulphate transporter gene (PDS). Nat Genet 1997, 17:411-422

8. Li XC, Everett LA, Lalwani AK, Desmukh D, Friedman TB, Green ED, Wilcox ER: A mutation in PDS causes non-syndromic recessive deafness. Nat Genet 1998, 18:215-217.

9. Johnsen T, Jørgensen MB, Johnsen S: Mondini cochlea in Pendred's syndrome. Acta Otolaryngol 1986, 102:239-247.

10. Nakagawa O, Ito S, Hanyu O, Yamazaki M, Urushiyama M: Female siblings with Pendred's syndrome. Int Med 1994, 33:369-372.

11. Reardon W, Trembath RC: Pendred syndrome - 100 years of underascertainment? Q J Med 1997, 90:443-447.

12. Campbell C, Cucci RA, Prasad S, Green GE, Edeal JB, Galer CE, Karniski LP, Sheffield VC, Smith RJ: Pendred syndrome, DFNB4, and PDS/SLC26A4 identification of eight novel mutation and possible genotypephenotype correlations. Hum Mutat 2001, 17:404-411.

13. Usami S, Abe S, Weston MD, Shinkawa H, Camp GV, Kimberling WJ: Nonsyndromic hearing loss associated with enlarged vestibular aqueduct is caused by PDS mutations. Hum Genet 1999, 104:188-192.

14. Park HJ, Shaukat S, Liu XZ, Hahn SH, Naz S, Ghosh M, Kim HN, Moon SK, Abe S, Tsukamoto K, Riazuddin S, Kabra M, Erdenetungalag R, Radnaabazar J, Khan S, Pandya A, Usami S-I, Nance WE, Wilcox ER, Riazuddin S, Griffith AJ: Origins and frequencies of SLC26A4 (PDS) mutations in east and south Asians: Global implications for the epidemiology of deafness. J Med Genet 2003, 40:242-248.

15. Tsukamoto K, Suzuki H, Harada D, Namba A, Abe S, Usami S: Distribution and frequencies of PDS (SLC26A4) mutations in Pendred syndrome and nonsyndromic hearing loss associated with enlarged vestibular aqueduct: a unique spectrum of mutations in Japanese. Eur J Hum Genet 2003, 11:916-922.
16. Japanese Archipelago Human Population Genetics Consortium, Jinam T, Nishida N, Hirai M, Kawamura S, Oota H, Umetsu K, Kimura R, Ohashi J, Tajima A, Yamamoto T, Tanabe H, Mano S, Suto Y, Kaname T, Naritomi K, Yanagi K, Niikawa N, Omoto K, Tokunaga K, Saitou N: The history of human populations in the Japanese Archipelago inferred from genome-wide SNP data with a special reference to the Ainu and the Ryukyuan populations. J Hum Genet 2012, 57:787-795.

17. Valvassori GE, Clemis JD: The large vestibular aqueduct syndrome. Laryngoscope 1978, 88:723-728.

18. Phelps PD: The basal turn of the cochlea. Br J Radiol 1992, 65:370-374.

19. Goldfeld M, Glaser B, Nassir E, Gomori JM, Hazani E, Bishara N: CT of the ear in pendred syndrome. Radiology 2005, 235:537-540.

20. Davidson HC, Harnsberger HR, Lemmerling MM, Mancuso AA, White DK, Tong KA, Dahlen RT, Shelton C: MR evaluation of vestibulocochlear anomalies associated with large endolymphatic duct and sac. AJNR Am J Neuroradiol 1999, 20:1435-1441.

21. Fraser GR: Association of congenital deafness with goiter (Pendred's syndrome): a study of 207 families. Ann Hum Genet 1965, 28:201-249.

22. Valvassori GE: The large vestibular aqueduct and associated anomalies of the inner ear. Otolaryngol Clin North Am 1983, 16:95-101.

23. Jackler RK, de la Cruz A: The large vestibular aqueduct syndrome. Laryngoscope 1989, 99:1238-1243.

24. Levenson MJ, Parisier SC, Jacobs M, Edelstein DR: The large vestibular aqueduct syndrome in children. Arch Otolaryngol Head Neck Surg 1989, 115:54-58.

25. Arcand $P$, Desrosiers M, Dube J, Abela A: The large vestibular aqueduct syndrome and seisorineural hearing loss in the pediatric population. J Otolaryngol 1991, 20:247-250.

26. Belenky WM, Madgy DN, Leider JS, Becker C, Hotaling AJ: The enlarged vestivular aqueduct syndrome (EVA syndrome). ENT J 1993, 72:746-751.

27. Okumura T, Takahashi H, Honjo I, Takagi A, Mitamura K: Sensorineural hearing loss in patients with large vestibular aqueduct. Laryngoscope 1995, 105:289-294.

28. Stinckens C, Huygen PL, Joosten FB, Van Camp G, Otten B, Cremers CW: Fluctuant, progressive hearing loss associated with Meniere like vertigo in three patients with the Pendred syndrome. Int J Pediatr Otorhinolaryngol 2001, 61:207-215.

29. Cremers CW, Admiraal RJ, Huygen PL, Bolder C, Everett LA, Joosten FB, Green ED, van Camp G, Otten BJ: Progressive hearing loss, hypoplasia of the cochlea and widened vestibular aqueducts are very common features in Pendred's syndrome. Int J Pediatr Otorhinolaryngol 1998, 45:113-123.

30. Dossena S, Rodighiero S, Vezzoli V, Nofziger C, Salvioni E, Boccazzi M, Grabmayer E, Botta G, Meyer G, Fugazzola L, Beck-Peccoz P, Paulmichl M: Functional characterization of wildtype and mutated pendrin (SLC26A4), the anion transporter involved in Pendred syndrome. J Mol Endocrinol 2009, 43:93-103.

31. Fugazzola L, Cerutti N, Mannavola D, Vannucchi G, Beck-Peccoz P: The role of pendrin in iodide regulation. Exp Clin Endocr Diab 2001, 109:18-22.

32. Scott D, Wang R, Kreman T, Sheffield V, Karniski L: The Pendred syndrome gene encodes a chloride-iodide transport protein. Nat Genet 1999, 21:440-443.

33. Scott DA, Wang R, Kreman TM, Andrews M, McDonald JM, Bishop JR, Smith RJH, Karnishki LP, Sheffield VC: Functional differences of the PDS gene product are associated with phenotypic variation in patients with Pendred syndrome and non-syndromic hearing loss (DFNB4). Hum Mol Genet 2000, 9:1709-1715.

34. Reardon W, Coffey R, Chowdhury T, Grossman A, Jan H, Britton K, KendallTaylor P, Trembath R: Prevalence, age of onset, and natural history of thyroid disease in Pendred syndrome. J Med Genet 1999, 36:595-598.

35. Napiontek U, Borck G, Muller-Forell W, Pfarr N, Bohnert A, Keilmann A, Pohlenz J: Intrafamilial variability of the deafness and goiter phenotype in Pendred syndrome caused by a T416P mutation in the SLC26A4 gene. J Clin Endocrinol Metab 2004, 89:5347-5351.

36. Iwasaki S, Tsukamoto K, Usami S, Misawa K, Mizuta K, Mineta H: Association of SLC26A4 mutation with clinical features and thyroid function in deaf infants with enlarged vestibular aqueduct. J Hum Genet 2006, 51:805-810.

37. Kitamura K, Takahashi K, Noguchi Y, Kuroishikawa Y, Tamagawa Y, Ishikawa K, Ichimura K, Hagiwara H: Mutations of the Pendred syndrome gene (PDS) in patients with large vestibular aqueduct. Acta Otolaryngol 2000, 120:137-141. 
38. Dai P, Li Q, Huang D, Yuan Y, Kang D, Miller DT, Shao H, Zhu Q, He J, Yu F, Liu X, Han B, Yuan H, Platt OS, Han D, Wu BL: SLC26A4 c.919-2A > G varies among Chinese ethnic groups as a cause of hearing loss. Genet Med 2008, 10:586-592.

39. Chen K, Wang $X$, Sun L, Jiang H: Screening of SLC26A4, FOXI1, KCNJ10, and GJB2 in bilateral deafness patients with inner ear malformation. Otolaryngol Head Neck Surg 2012, 146:972-978.

40. Wu CC, Yeh TH, Chen PJ, Hsu CJ: Prevalent SLC26A4 mutations in patients with enlarged vestibular aqueduct and/or Mondini dysplasia: a unique spectrum of mutations in Taiwan, including a frequent founder mutation. Laryngoscope 2005, 115:1060-1064.

41. Shin JW, Lee SC, Lee HK, Park HJ: Genetic screenig of GJB2 and SLC26A4 in Korean cochlear implantees: experience of soree Ear clinic. Clin Exp Otorhinolaryngol 2012, 30(Suppl 1):10-13.

42. Yang JJ, Tsai CC, Hsu HM, Shiao JY, Su CC, Li SY: Hearing loss associated with enlarged vestibular aqueduct and Mondini dysplasia is caused by splice-site mutation in the PDS gene. Hear Res 2005, 199:22-30.

43. Wang QJ, Zhao YL, Rao SQ, Guo YF, Yuan H, Zong L, Guan J, Xu BC, Wang DY, Han MK, Lan L, Zhai SQ, Shen Y: A distinct spectrum of SLC26A4 mutations in patients with enlarged vestibular aqueduct in China. Clin Genet 2007, 72:245-254.

44. Reyes S, Wang G, Ouyang X, Han B, Du LL, Yuan HJ, Yan D, Dai P, Liu XZ: Mutation analysis of SLC26A4 in mainland Chinese patients with enlarged vestibular aqueduct. Otolaryngol Head Neck Surg 2009, 141:502-508.

45. Huang S, Han D, Yuan Y, Wang G, Kang D, Zhang X, Yan X, Meng X, Dong M, Dai P: Extremely discrepant mutation spectrum of SLC26A4 between Chinese patients with isolated Mondini deformity and enlarged vestibular aqueduct. J Transl Med 2011, 30:167.

46. Krawczak M, Reiss J, Cooper DN: The mutational spectrum of single basepair substitutions in mRNA splice junctions of human genes: causes and consequences. Hum Genet 1992, 90:41-54.

47. Larriba S, Bassas L, Gimenez J, Ramos MD, Segura A, Nunes V, Estivill X Casals T: Testicular CFTR splice variants in patients with congenital absence of the vas deferens. Hum Mol Genet 1998, 7:1739-1744.

48. Betsalel OT, Rosenberg EH, Almeida LS, Kleefstra T, Schwartz CE, Valayannopoulos V, Abdul-Rahman O, Poplawski N, Vilarinho L, Wolf P, den Dunnen JT, Jakobs C, Salomons GS: Characterization of novel SLC6A8 variants with the use of splice-site analysis tools and implementation of a newly developed LOVD database. Eur J Hum Genet 2011, 19:56-63.

doi:10.1186/1471-2350-14-56

Cite this article as: Ganaha et al:: Pathogenic substitution of IVS15 + 5G > A in SLC26A4 in patients of Okinawa Islands with enlarged vestibular aqueduct syndrome or Pendred syndrome. BMC Medical Genetics 2013 $14: 56$.

\section{Submit your next manuscript to BioMed Central and take full advantage of:}

- Convenient online submission

- Thorough peer review

- No space constraints or color figure charges

- Immediate publication on acceptance

- Inclusion in PubMed, CAS, Scopus and Google Scholar

- Research which is freely available for redistribution 